\title{
Hybrid Assistive System-The Motor Neuroprosthesis
}

\author{
DEJAN POPOVIC, RAJKO TOMOVIĆ, AND LASZLO SCHWIRTLICH
}

\begin{abstract}
Two approaches are currently applied for motor rehabilitation of paralyzed humans: functional electrical stimulation (FES) and mechanical bracing. Both assistive systems have limited application due to several factors (indication, psycho, socio, and economic status, state-of-the-art of technology, etc.). The combination of FES and an externally powered and controlled brace is called a hybrid assistive system (HAS). The HAS presented in this paper is a combination of multichannel surface FES and self-fitting modular orthosis (SFMO). Energy expenditure and a reduction of force load on the upper extremities are criteria for the efficacy of HAS. The control system of HAS is nonnumerical and based on artificial reflexes (AR).
\end{abstract}

\section{INTRODUCTION}

$\mathrm{M}$ OBILITY of the severely handicapped (paraplegic, quadriplegic, and similar) relies very much on wheelchair propulsion that can restrict many of their activities and social readaptation. Existing techniques for gait restoration are still not widely used. External braces are bulky and unpleasant for frequent daily fixing. They are meant for low speed swing - to or swing-through gait patterns involving upper extremities as power sources, as well as supports for balance maintenance. Active external skeletons [36], [14], [28] were never applied in the environment other then at research centers. Some of the developed systems should be considered for different applications like standing and walking training [36], or bracing of muscular dystrophy patients [14]. In order to overcome shortcomings of other exoskeletons, a self-fitting modular orthosis (SFMO) was designed [26], [43]. Details on the SFMO are described elsewhere [27]-[29].

Most of current research activities in gait restoration of paralyzed patients is related to functional electrical stimulation. FES provides or improves functional movements of an abnormal neuromuscular system by the application of electrical pulses to the efferent or afferent peripheral nerve fibers. These pulses are supplied by either surface, percutaneous, or implanted electrodes and they are externally controlled. In addition to immediate functional motor effects in some patients, FES may also improve volitional motor control of the paretic extremity and reduce spasticity even after electrical stimulation is discontinued. In cases of clinically complete paralysis, no improvement of volitional motor control can be expected, but daily electrical stimulation increases the contractile force of the hypotrophic muscle [49].

Manuscript received June 5, 1988; revised December 2, 1988

The authors are with the Faculty of Electrical Engineering, University of Belgrade, 11000 Belgrade, Yugoslavia.

IEEE Log Number 8927444
External control is needed in all of active orthotic devices. Dynamical analysis of limb motion was pioneered by Bernstein [51]. These results were used to determine how external torque modulate joint torque and affect limb trajectories. Such a method involves numerical control in the process of gait synthesis. However, basic research results in neurophysiology point out the different nature of control in man and animal. The simplest behavioral acts are reflexes [10] that are elicited by particular types of sensory stimuli. One of the best known is the patellar reflex where the primary afferent fibers from muscle spindles act directly on motor neurons to produce brisk knee extension [38]. Higher centers, such as the motor cortex have executive control of the whole motor system [25]. Although such general ideas are widely accepted, the details and specific roles remain obscure. For example, the role of even simplest spinal pathway, the monosynaptic reflex remains controversial [52].

Artificial reflex (AR) control has influenced the development of nonnumerical control methods. Nonnumerical control of locomotion was proposed by Tomovic [21], [41]. This nonnumerical approach has been developed into the concept of artificial reflex (AR) control [45]. Development of artificial intelligence (AI) methodology stimulated the development of skill based expert systems [46][48]. It is important to remark that in spite of the on-off behavior of neurons human functional movements are smooth. Consequently, at the lowest control level, AR must deal with dynamical properties of the system. Some of the existing methods [11], [12], [50], [13] may be incorporated efficiently in AR control.

The properties of skill-based expert systems controlling assistive devices are the following:

- The control algorithm must fit the nonnumerical nature of motor control in man.

- Expert systems can be easily organized in a hierarchical structure.

- Expert system methods can be used for independent scene analysis, motion planning, and motion execution.

Hybrid assistive system (HAS) represents a combination of functional electrical stimulation (FES) and a selffitting modular orthosis (SFMO) controlled by artificial reflexes (AR) (Fig. 1). Such a HAS may be interpreted as an external neuroprosthesis for gait restoration of severely handicapped. HAS was firstly suggested by Tomovic [42] long before the rehabilitation technology was able to meet the requirements. Development of an active SFMO, specifically its modularity and the cybernetic actuators, was intended to integrate FES and an active mechanical brace. 


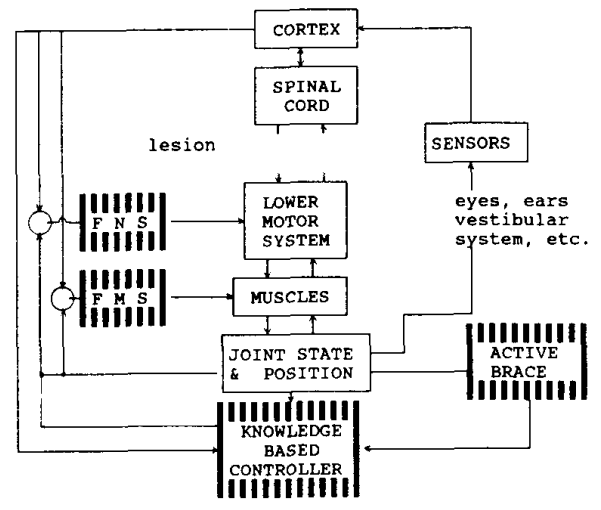

Fig. 1. Functional model of the HAS. Voluntary control of locomotion is presented by direct vertical path. The direct path is disrupted by the lesion. HAS model involves two assistive devices working in parallel. The left side relates to functional electrical stimulation acting as functional nerve stimulation (FNS) and as functional muscle stimulation (FMS). The right side pertains to active external skeleton (SFMO). Direct intervention of the patient is presented by the line connecting cortex and the controller box. It is realized by switch control or prescribed body movements. Both closed loops, the FES, and the active brace use artificial sensors such as force, velocity, and position transducers.

The first HAS application was reported during a clinical evaluation of the SFMO [29]. The group working with Andrews (Strathclyde University, Glasgow) has accepted the idea of hybrid assistive systems [1], [2] with nonnumerical control. The first stage of this work was similar to our preliminary control method for gait synthesis, i.e., the application of finite state control [44]. The parallel application of external skeleton brace and FES has been tested in other centers as well [24]. Encouraging recent results related to HAS have been presented by the Strathclyde Group [3]-[5]. They differ from our approach in two basic ways: use of braces without actuators and the development of example based-systems. Their approach is rather an extension of FES then a parallel application of two assistive systems. The work with implanted electrodes and a brace performed in Cleveland VA Center [5], [20] is a new step in HAS applications.

\section{Model of the Hybrid Assistive System}

Application of FES for gait restoration was firstly developed in Ljubljana, Yugoslavia [16], [17], [8]. Currently, it is in clinical application in several rehabilitation centers throughout the world [23], [19], [4] and limited home use.

For disabilities involving several muscle groups, preprogrammed multichannel stimulator has been developed [17], [8], [9], [19], [15], [22], [23].

Based on experience with different types of braces, we decided to use as an active external skeleton SFMO [26], [29]. The biomechanical model of the SFMO [26], [27] involves partially active external skeleton, soft interface, and the modular design. The model and a complete paraplegic with SFMO are presented in Fig. 2 .
Main features of the SFMO are as follows:

- Self adjusting of the brace to the body through telescopic elements.

- Soft interface by special trousers. A favorable pressure and force distribution exists due to surface interface.

- The device is unilateral.

- Weight of the brace is reduced compared to most other devices.

- Modular construction allows independent application of any of six joints. Left and right side are not connected except in the cases when trunk stabilization is needed.

- Motion is obtained by special motor units. Units are dislocated from the joints (cable operated). Motor units are controlling stiffness of the joint from loose (free) to rigid (locked) state, and joint motion (flexion-extension). The operation of actuators is explained elsewhere [35].

The clinical experience has proved that the SFMO can be used as a brace under valid orthotic principles [39], [40], [30]-[32].

The crucial issue in the development of such a complex system is the control, which, in our case, is based on artificial reflexes.

The term artificial reflex as used in this context has no ambition to be equivalent of its counterpart in neural networks. Nonetheless, it reflects some rudimentary features of reflex loop reactions in the nature. The term is used in the following way:

- Externally powered and controlled joint is activated by artificial proprioceptive and exteroceptive sensors.

- Input to the joint controller is used for recognition of sensory patterns. Patterns are recognized by nonnumerical, logical expressions.

- Recognized sensory patterns are directly matched to one of the actuator states: loose and locked states, flexion, and extension.

The pattern matching operator (rules) is derived by knowledge capturing using gait records.

Expert system for movement control consists of following blocks: data acquisition, database, general rule base.

Knowledge base includes the database, formed by scanning system input and prehistory of the system, working and general rulebase.

General rulebase has three subsets of rules: regular, hazard, and mode rules. The term rule corresponds to the reflex activity of externally controlled electrical stimulation or brace. Rules are stored in memory in arbitrary order (Fig. 3).

"Firing" of a rule from the normal rule base changes the actuator state (locking, unlocking, extension, or flexion).

Mode base consists of rules defining the gait mode. Firing of a rule from the mode base transfers the corresponding subset of rules from the general rule base to the working memory (Fig. 4).

The rule in our case is a Boolean expression. The left side is a sensory pattern, and the output acts upon FES or 


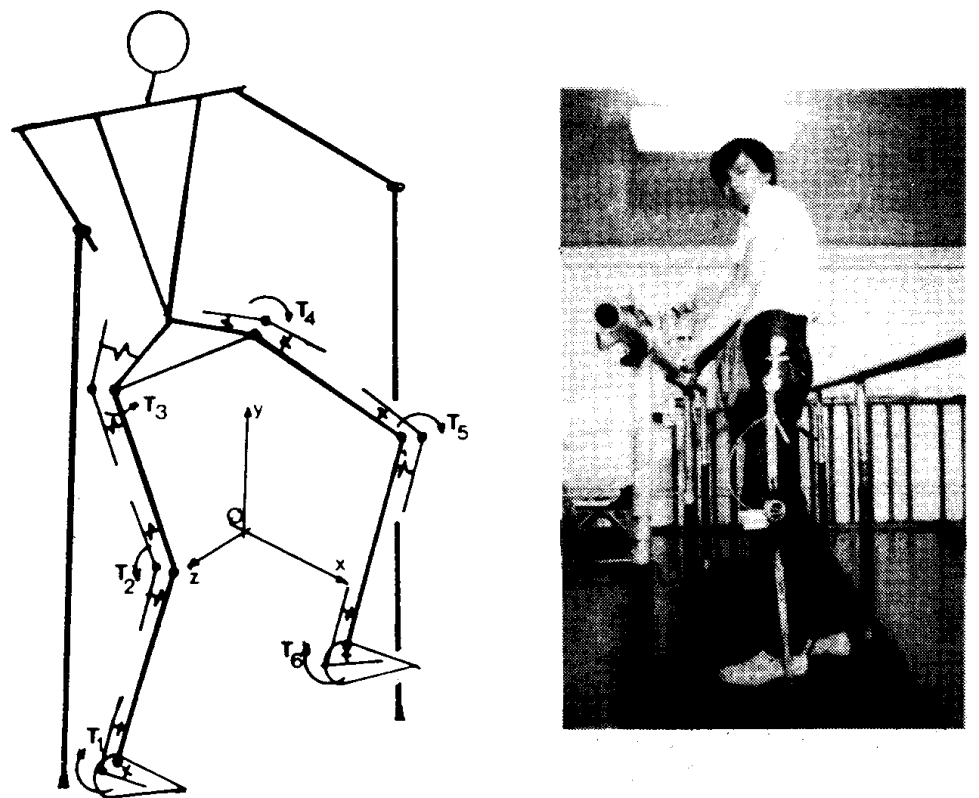

Fig. 2. Biomechanical model of the SFMO. $T_{i}$ are externally powered torques provided by Cybernetic Actuators (CA), coefficients of viscoelastic interface forces between the brace and body are $c$. The application of the SFMO is presented in T 10/11 complete paraplegic ("Dr. Miroslav Zotovic" Rehabilitation Institute, Belgrade)

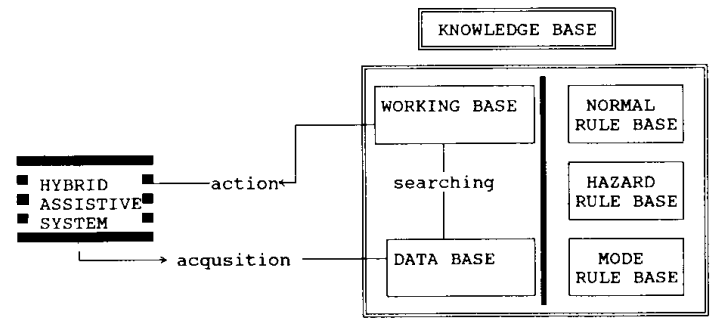

Fig. 3. Schematic presentation of control algorithm.

\begin{tabular}{|l|l|c|}
\hline \multirow{2}{*}{$\begin{array}{c}\text { SENSORY } \\
\text { PATTERN } \\
\downarrow \\
\text { MOTOR } \\
\text { ACT }\end{array}$} & NORMAL RULE BASE & REGULAR MOVEMENTS \\
\cline { 2 - 3 } & HAZARD RULE BASE & ADAPTATION WITHIN THE MODE \\
\cline { 2 - 3 } & UNEXPECTED SITUATION \\
\hline \hline $\begin{array}{c}\text { SENSORY } \\
\text { PATTERN } \\
\begin{array}{c}\text { ROM-RAM } \\
\text { ACT }\end{array}\end{array}$ \\
\hline
\end{tabular}

Fig. 4. General rulebase.

cybernetic actuators controlling the brace, or upon the working base organization. For example, a mode rule has the form

If

the pressure existing in the left sole is bigger then the one in the right sole, and

the pressure on metatarsal area of the left sole is bigger then the pressure in the heel area of the left shoe sole, and

the left knee angle is close to $180^{\circ}$,

and

the left shank is close to the vertical line,

then

the intention for gait initiation with the right leg is recognized.

If the previous standing was on flat ground, the regular database in RAM will be filled with the set of rules for ground level walking. Consequently, the right leg flexor reflex will be initiated, and the $\mathrm{CA}$ on the brace of the right leg will be in free state.

Formal expression for above action reads as follows:

$$
\begin{aligned}
& \left(p^{l}-p^{r}-d_{0}\right)\left(p_{m}^{l}-p_{t}^{l}-d_{0}\right) \\
& \quad \cdot\left(\Phi_{k}-180^{\circ}-d_{0}\right)\left(\alpha-d_{0}\right)=X=1 .
\end{aligned}
$$

Symbols used in the above expression are $p$ for pressure, $l$ for left, $r$ for right, $t$ for toe, $h$ for heel, $\phi_{k}$ for knee angle, $d_{0}$ for ADC increment.

The set of rules for this type of HAS is not closed. The study of gait performance of paralyzed patients may be obtained by iterative procedure. Iteration means "trials and errors" method. The term "error" refers to efficacy and quality of the gait. Sensors used in the HAS are force transducers located in the insoles of each shoe at toe and 
heel zones, knee angle potentiometer, and a pendulum type potentiometer for shank displacement from the vertical line. The input vector has eight components. Software provides information about angular velocities, and also process force information providing information about center of pressure displacement during stance phase. The searching procedure (Sensory Acquisition and Motion execution) is $20 \mathrm{~ms}$ in the current version of the portable $\mu$ computer. The number of rules is limited with unique representation within existing sensory information basis. The knowledge system has been tested with 96 rules for $\mathrm{A} / \mathrm{K}$ (above/knee) prosthesis. The control for HAS operates with only 23 rules, comprising level walking, ramp climbing, backward walking, standing up, sitting down, and turning around. Clearly the set of rules depends on the type of motor deficiency and HAS technology.

Artificial intelligence systems are capable of learning. This feature has not been included in the system. Efforts to use machine learning for different type of HAS have been reported [5], [6]. Current experience points out individual needs of each patient require special programming. Such programming is straightforward by the use of a PC computer and may be achieved on line [29].

\section{EXPERIMENTAL WORK AND Results}

Among a number of options (paraplegic, quadriparetic, incomplete quadriplegic, paraparetic) for HAS application the preference was given to an incomplete quadriplegic patient. The evaluation has been carried out in the Rehabilitation Institute "Dr. Miroslav Zotovic'" in Belgrade. The incomplete lesion was selected because such a patient is able to ambulate either with FES or brace or HAS. The use of HAS was compared with FES and SFMO.

Energy consumption and ground force reactions were used as objective criterions for comparison of the system. In addition, gait mode, maximal speed, maximal slope, maximal length of functional use were compared.

A case history can be presented of an patient, male, 24, traumatic injury two years prior to treatment, C 5/C 6 incomplete lesion, abdominal musculature well preserved, poor arm and hand control, arm muscles week (antigravitation tasks are hardly possible or impossible), no sensations and volitional control in lower extremities (complete functional lesion above the waist), extension spasms, extremely eager to regain walking and standing. The patient was trained to stand and walk in parallel bars, with the walker or under elbow crutches. He was trained to use each component of the system independently with equal personal acceptance in order to obtain objective comparison.

The SFMO consisted of two active modules (knee mechanisms) and two ankle joints with spring mechanisms for dorsal flexion. FES system consisted of a sixchannel surface stimulator. Stimulation of gluteus medius $\mathrm{m}$., quariceps $\mathrm{m}$. and peroneal $\mathrm{n}$. on both sides was applied. The on-off stimulation was used. Each channel was set to appropriate parameters $(I, T, f)$. Maximal current was limited to $140 \mathrm{~mA}$, maximal duration $=0.5 \mathrm{~ms}$, frequency range $20-45 \mathrm{~Hz}$. The sensory feedback was implemented by a Bourns potentiometer, a pendulum damped potentiometer (Humprey, San Diego) and Interlink force transducers (resistive Wheatstone bridge). Hand support (walker and crutches) were equipped with strain gauge transducers and switches. Sensory information from walker/crutches was performance assessment, not for control purposes. Controller was based on INTEL 8085 $\mu$ processor, ADC $0816 \mathrm{CCN}$ AD converter, D8155, 32 kbytes ROM memory, 6116 chip with 2 kbytes RAM memory with serial and parallel communication with Intel IV development system, $8 \mathrm{MHz}$ clock, and power stage. CA used for powered knee is based on prosthetic CA actuator described in details elsewhere [29]. The knee joint is remotely actuated by a flexible push-pull cable.

Programming is done by the use of Intel assembler [53]. The Intel IV system is used for on line adaptation of parameters. Experimental analysis (TV system, goniometric system) was combined with computer simulation of the SFMO model.

Prior to gait analysis, the muscle fatigue resistance and maximal joint torques were measured. The test was performed in order to determine the length of the use of the FES system in functional range. Fig. 5 presents the endurance test performed in an incomplete C 5 / C 6 patient. Quadriceps m. stimulation with monophasic constant current $(I=100 \mathrm{~mA}$, pulse width $T=250 \mu \mathrm{s}$, frequency $f$ $=20 \mathrm{~Hz})$ is used for knee extension.

Flexion reflex during standing in parallel bars was estimated in the following way. Ipsilateral peroneal $n$. (flexion reflex, $f=20 \mathrm{~Hz}, T=300 \mu \mathrm{s}, I=45 \mathrm{~mA}$ ) was stimulated and the contralateral leg was braced with SFMO. Stimulation parameters were selected according results published by Ljubljana REC group [18].

The flexion reflex deteriorates with the time. After 10 min stimulation ( $5 \mathrm{~s}$ stimulation, $5 \mathrm{~s}$ relaxation) movement loses its functionality. Maximal length of effective stimulation is limited to $10 \mathrm{~min}$. Ambulation tests in parallel bars have confirmed the same result. First 10 min of gait correspond to normal flexion-extension synergy.

An important indicator of gait efficiency is velocity. Speaking of normal walking, we are usually referring to a velocity between 1 and $1.5 \mathrm{~m} / \mathrm{s}$. Average maximal speed was recorded from then tests:

$$
v_{\mathrm{SFMO}}=0.6 \mathrm{~m} / \mathrm{s} \quad v_{\mathrm{FES}}=0.45 \mathrm{~m} / \mathrm{s} \quad v_{\mathrm{HAS}}=0.66 \mathrm{~m} / \mathrm{s}
$$

The angle range for slope walking is in range of

$$
\begin{gathered}
\alpha_{\mathrm{SFMO}}=\left(-4^{\circ}, 4^{\circ}\right) \quad \alpha_{\mathrm{FES}}=\left(-7^{\circ}, 5^{\circ}\right) \\
\alpha_{\mathrm{HAS}}=\left(-7^{\circ}, 5^{\circ}\right) .
\end{gathered}
$$

The oxygen consumption is normalized to energy consumption of a healthy subject, biomechanically similar to our patient (male, same height, similar mass distribution, 


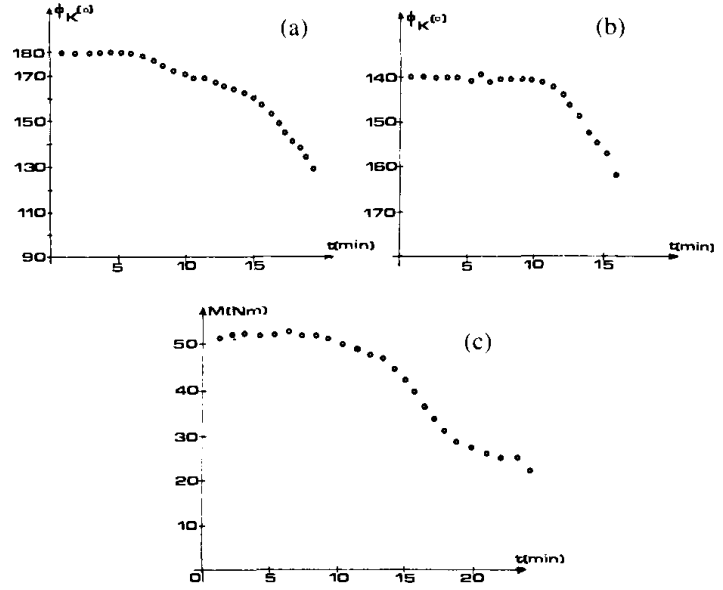

Fig. 5. Angle versus time in incomplete C 5/C6 quadriplegic; (a) isokinetic knee extension, (b) isokinetic knee flexion, (c) isomorphic knee extension. In extension initial angle is $90^{\circ}$, in flexion initial angle is $180^{\circ}$. The test was performed during regular every day stimulation procedure. Maximal torque in isometric stimulation (shank in vertical position, knee angle $90^{\circ}$ ) is presented. Mean value from ten trials is pre sented.

same weight, 23 years). Using $V_{0}=1$ as a normal value, we got $\left(V_{0}=7.9 \mathrm{mg} / \mathrm{kg} / \mathrm{min}\right)$ the results tabulated in Table I.

As seen energy consumption decreases when HAS is applied. This statement is qualitative because only a single patient was examined and the results depend on the type of impairment. All the measurements were done in laboratory conditions; muscle fatigue is estimated to be the same at the beginning of each task. Measurements are performed in separate sessions.

HAS provides wider variety of gait modes compared to its components.

The real advantage of HAS over FES is due to the fact that the brace is applied in standing and stance phase. Extensor muscles are activated only in order to produce movement, not to stabilize specific position. Theoretically, HAS use is not limited in time. Muscle fatigue does not play major role. Practically, HAS use is limited with dizziness of patient and overall fatigue. The dizziness appearing in high thoracic and cervical lesions is due to the lack of blood pressure control in paralysis. Even when this mechanism is intact the blood supply of brain seems to be below the physiological once the patient is standing. This phenomenon is more prominent during quiet standing than when patient is active (walking, hand/arm activity). Energy expenditure is still almost double compared to consumption in normal gait. Slow walking is the main reason for low efficiency.

Ground reaction forces (Kistler force platform) and arm forces with strain gauges in under elbow crutches were also recorded. The gait speed was $v=0.45 \mathrm{~m} / \mathrm{s}$ (Fig. 6). Arm forces for different velocities with HAS was ob. served and force decrease with velocity increase was noticed. This is due to D'Alembert (inertial) forces. Slow
TABLE I

Normalized Energy Consumption of Paraplegic Patient Walkino With an Assistive System. HAS-Hybrid Assistive System; FESFunctional Electrical Stimulation; SFMO--Self-Fitting Modular Orthosis; $V$-Energy Consumption of Paraplegic Patient, $V_{0}-$ Energy CONSUmption of Normal Sl'bJect

\begin{tabular}{|c|c|c|c|c|}
\hline & SEMO & FES & HAS & \\
\hline \multirow[t]{5}{*}{$\mathrm{v} / \mathrm{v}_{0}$} & 3.6 & 2.4 & 1.9 & ground level, $\mathrm{v}=0.4 \mathrm{~m} / \mathrm{s}$ \\
\hline & 3.9 & 2.5 & 1.9 & slope, $-4^{\circ}, \quad v=0.3 \mathrm{~m} / \mathrm{s}$ \\
\hline & 4.7 & 4.0 & 2.9 & slope, $+4^{\circ} . \quad \mathrm{v}=0.3 \mathrm{~m} / \mathrm{s}$ \\
\hline & 3.9 & 1 & 1.7 & ground level, $\mathrm{v}=0.6 \mathrm{~m} / \mathrm{s}$ \\
\hline & I & 1 & 1.6 & ground level, $\mathrm{v}=0.66 \mathrm{~m} / \mathrm{s}$ \\
\hline
\end{tabular}

walking is a quasi-static event; normal and fast gait are dynamical phenomena (Fig. 7).

Ground reaction forces on arms and legs are practically equal in swing to or swing through gait [Fig. 6(a)]. Horizontal forces are very low. When walking with six channel FES, arm reactions are much smaller then with the use of external skeleton. However, the peak value is rather remarkable. The peak is due to the transfer of the body weight from ipsilateral to contralateral limb. The sum of both arm reactions is presented [Fig. 6(b)]. The use of HAS reduces slightly the hand forces. The speed such obtained is not adequate. Inertial forces are still not large enough in this range of accelerations and velocities. Fig. 7 presents the improvement of arm forces while increasing the gait speed. The step is longer, flexion phase is shorter, duration of stimulation is just 32 percent of gait cycle. It is necessary to point out that this gait is far behind the pattern which may be compared with normal locomotion. Balance is poor, gait speed is limited, arms are used as power generators, etc.

\section{CONCLUSION}

Gait restoration is an important task in the rehabilitation process. Nonetheless, only a certain number of highly motivated paralyzed will use orthotic systems instead of wheelchair. Neuroprosthetics may become a crucial tool in abandoning sitting mobility and regaining bipedal activities. The hybrid assistive system (HAS) was designed to provide additional power to externally controlled muscle actions when needed.

Application of nonnumerical control has proved to be an efficient method for gait restoration. Essential features of the approach are as follows:

- Great evolutionary potential since it relies on the knowledge transfer from man to machine. Development of learning capabilities and better understanding of neurophysiological mechanisms will definitely improve mobility control.

- Implant stimulation technique can be also integrated into HAS using the same control concept.

In conclusion one can assert that HAS is a new step in the development of neuroprostheses for locomotion and manipulation. HAS improves mobility and feeling of safety of the handicapped. SFMO and cybernetic actua- 

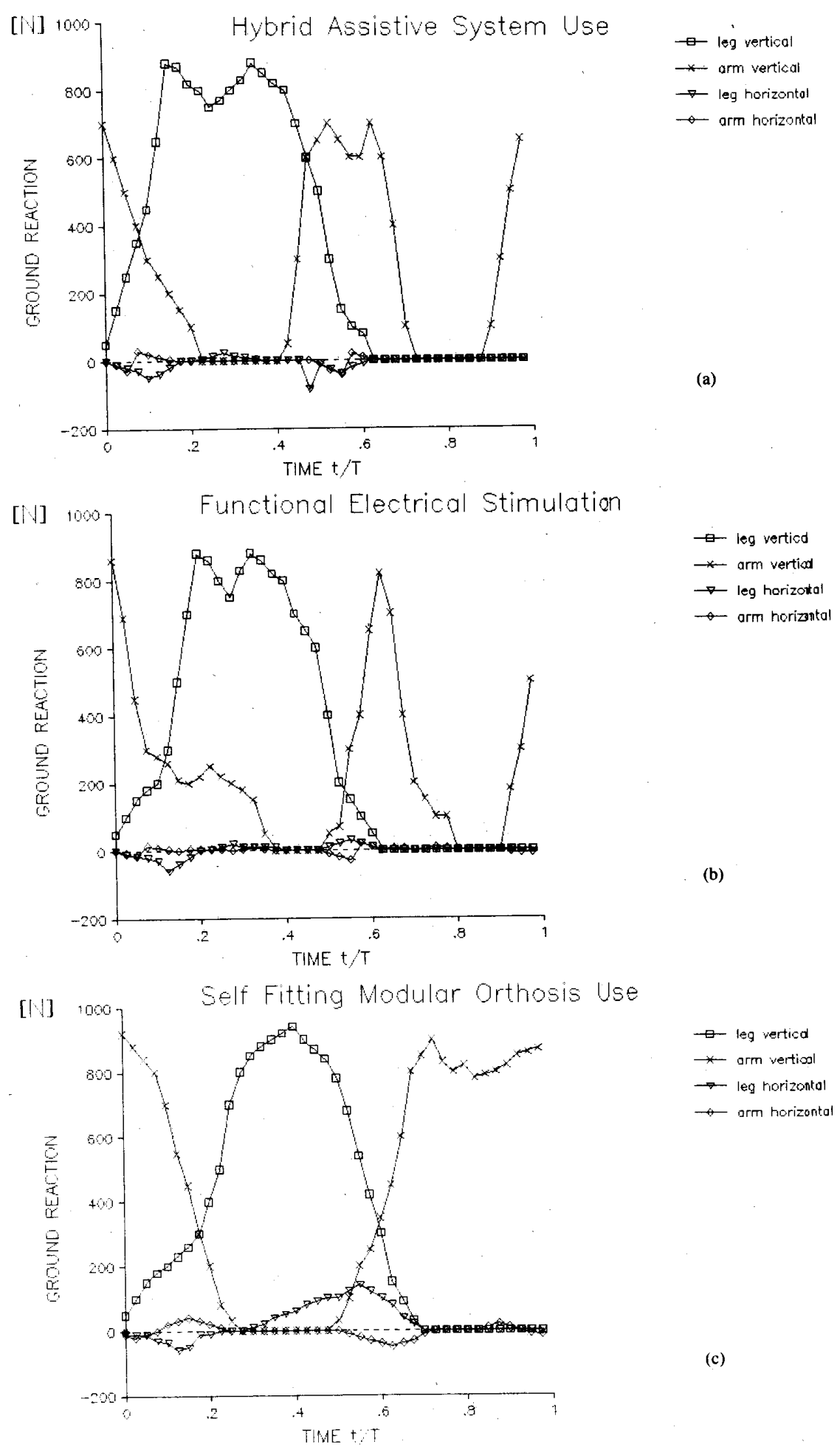

(b)

Fig. 6. Ground reaction (horizontal and vertical) in incomplete quadriplegic (C5/C6) patient. (a) Use of SFMO, (b) use of FES, (c) use of HAS. Gait speed is $v=0.45 \mathrm{~m} / \mathrm{s}$, ground level walking, step length is $L=0.8 \mathrm{~m}$, step cycle $T=1.44 \mathrm{~s}$. Patient is $m=70 \mathrm{~kg}, H=1.72 \mathrm{~m}$. 


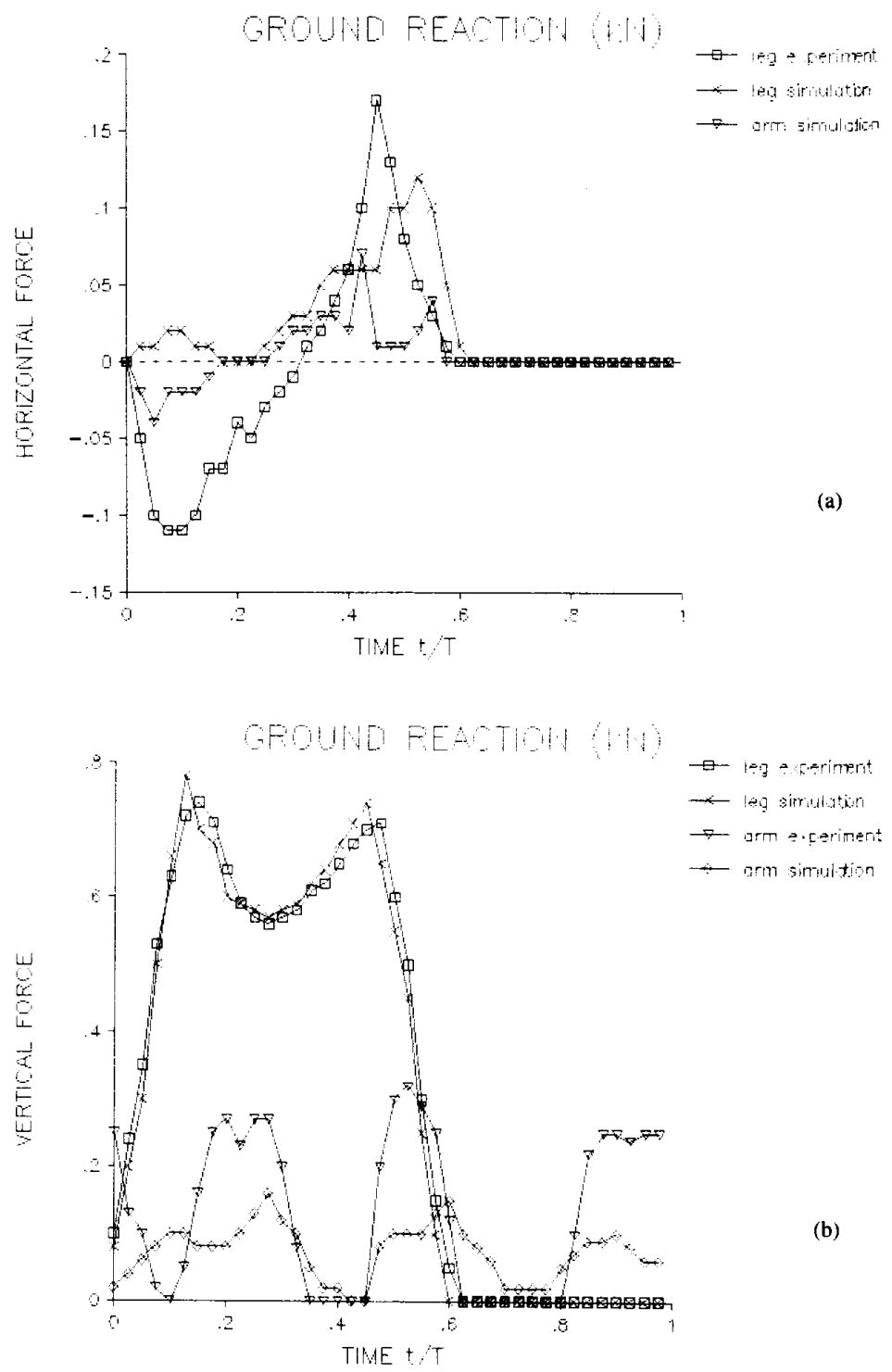

Fig. 7. Ground force reaction in quadrupedal incomplete quadriplegic gait. The velocity is $v=0.66 \mathrm{~m} / \mathrm{s}$. The figure shows simulation of the model and experimental result in HAS use. Upper figure presents vertical ground reaction, and lower one horizontal. Gait cycle is $t=1.4 \mathrm{~s}$, the step length $L=94 \mathrm{~cm}$.

tors are essential contributions to HAS as a neuroprosthesis.

Artificial reflex control has also added new quality to existing assistive systems.

\section{REFERENCES}

[1] B. Andrews and T. Bajd, Hybrid Orthoses for Paraplegics, in Ad vances in External Control of Human Extremities VIII, (supplement). Yugoslav Committee for ETAN, Beograd, 1984, pp. 55-61.

[2] —-, "Paraplegic locomotion: A hybrid FES approach," Proc. Abano Terme Meet. Rehab., Padova, pp. 195-198, 1985.

[3] B. Andrews and R. Baxendale, "A hybrid orthosis incorporating artificial reflexes for spinal cord damaged patients," J. Physiol., vol $380,1988$.
14] B. Andrews et al., A Hybrid Orthosis for Paraplegics Incorporating Feedback Control, in Advances of External Control of Human Extremities IX. Yugoslav Committee for ETAN. Beograd, 1987, pp. 297-311.

[5] — "Hybrid FES orthosis incorporating closed loop control and sensory feedback." J. Biomed. Eng., vol. 10, no. 2. pp. 128-134. 1988.

[6] - "Rule based control of a hybrid FES orthosis," Proc. IFAC Symp. Model. Contr. Biomed. Systems. 1988.

[7] B. Andrews, "Lower limb hybrid FES orthoses: Rule based control neural prostheses: Motor system." Eng. Foundation Conf. . Potosi. Missouri, pp. 43-48, 1988.

[8] T. Bajd $e t$ al.. "Standing up of a healthy subject and a paraplegic patient." J. Biomechan., vol. 15. no. 1. pp. 1-10. 1982.

[9] B. Bowman et al., "Gait assist and training." Annu. Rep. Rancho Rehab. Eng. Center, pp. 18-22, 1981.

[10] T. Carew. "The control of reflex action." in Mofor Sistem of the 
Brain: Reflex and Voluntary Control of Movements, 1986, pp. 457468.

[1!] P. Crago et al., "Closed-loop control of force during electrical stimulation of muscles," IEEE Trans. Biomed. Eng.. vol. BME-27, pp. $306-312,1980$

[12] _ - "Task control, neural prostheses: Motor system," presented at Eng. Found. Conf., Potosi, MO, 1988, pp. 34-35.

[13] H. Chizeck, "Controlled multiple degree-freedom system, neural prostheses: Motor system,"' presented at Eng. Found. Conf., Potosi, MO, 1988, pp. 36-42.

[14] D. Hristic et al., "New model of autonomous active suit for dystrophic patients,' in Advances in External Control of Human Extremities VII. Yugoslav Committee for ETAN, Beograd, 1981, pp. 3342 .

[15] J. Kawamura, "Clinical experience of functional electrical stimulation," in Japan, Proc. of Rehab. Eng. Internat. Seminar, REIS-80, Tokyo, 1982, pp. 72-86.

[16] A. Kralj et al., "Experience with FES enabled standing in complete paraplegic patients," in Advances in External Control of Human Extremities. Yugoslav Committee for ETAN, Beograd, 1981, pp. 297304

[17] L. Kralj et al.. "Electrical stimulation providing functional use of paraplegic patient muscles," Med. Prog. Technol., vol. 7, pp. 3-9, 1980 .

[18] A. Kralj et al., REC Ljubljana, Final Report 1983-1987, NIDRR, Washington, D.C. (available from REC, Ljubljana, Ljubljana).

[19] E. B. Marsolais et al., "Functional walking in paralyzed patients by means of electrical stimulation," Clin. Orth. Rehab. Res., vol. 175, pp. 30-36, 1983.

[20] E. B. Marsolais, "Surgical consideration in lower extremity FNS, neural prostheses: Motor system,"' presented at Eng. Found. Conf., Potosi, MO, 1988, pp. 64-67

[21] R. McGhee, "Finite state control of legged locomotion," Math. Biosci., vol. 2, no. 1/2, 1988.

[22] H. Peckham et al., "Controlled prehension of hands release in the C5 quadriplegic elicited by functional electrical stimulation of the paralyzed forearm musculature," Ann. Biomed. Eng., vol. 8, pp. 388396. 1988.

[23] J. Petrofsky et al., " Constant-velocity contractions in skeletal muscle efferents," Med. Biol. Eng. Comput., vol. 17. pp. 583-591. 1979.

[24] - "A computer controlled walking system: The combination of an orthosis and FES," J. Clin. Eng., vol. 11, no. 2, pp. 121-133, 1986.

[25] G. Phillips et al., "Corticospinal neurones: Their role in movement." Monograph Phys. Soc., no. 34. London: Academic, 1977.

[26] D. Popovic et al. "Neue Aspekte für den Bau fon Orthesen für die Untheren Extremitaten," Ortopadie Technik, vol. 6, pp. 94-97, (in German), 1979

[27] - . "The biomechanics of the self-fitting modular orthoses, " $J$. Biomech. Tokyo, pp. 24-39, (in Japanese), 1980.

[28] _ " "Assistive devices for gait restoration," Ph.D. thesis, Faculty of Electrical Engineering, University of Belgrade, Belgrade.

[29] - - Tech. Clin. Eval. Self Fitting Modular Orthoses (SFMO), Prog ress and final report, NIDRR, Washington, D.C., project 432.

[30] D. Popovic and L. Schwirtlich, "External brace for hybrid system," in Proc. IV Mediterranean Conf. Biomed. Eng., Sevilla, 1986, pp 25-28.

[31] D. Popovic, "Hybrid systems for motion restoration," in Artificial Organs. New York: VCH Pub., 1987, pp. 531-542.

[32] - Gait Restoration by Active SFMO, IFAC Monography Control Aspects in Biomedical Robotics. New York: Pergamon, 1987, pp. $84-94$

[33] - "Hybrid powered orthoses," in Advances in External Control of Human Extremities IX. Yugoslav Committee for ETAN, pp. 95104,1987

[34] D. Popovic, "Hybrid assistive system, neural prostheses: Motor system," Eng. Found. Conf., Potosi, MO, 1988, pp. 49-50.

[35] M. Popovic and D. Popovic, "Cybernetic actuator for orthosis/prosthesis," in Proc. XXVII Yugoslav Symp. ETAN, II, 1983, pp. 285292.

[36] P. Rabishong et al., "AMOLL project," in Advances in External Control of Human Extremities $V$. Yugoslav Committee for ETAN, 1975, pp. 33-44.

[37] U. Stanic et al., "Multichannel electrical stimulation for correction of hemiplegic gait," Scand. J. Rehab. Med., vol. 10, pp. 75-92, 1978
[38] R. B. Stein et al. " Modification of muscle responses by spinal circuitry," Neurosci., vol. 11, no. 1, pp. 231-240. 1984.

[39] L. Schwirtlich, S. Kovacevic. and D. Popovic, "Clinical evaluation of the SFMO in spastic paraplegics," in Advances in ECHE VII. Yugoslav Committee for ETAN, Beograd, Yugoslavia, 1981, pp. 29 42

[40] L. Schwirtlich and D. Popovic, "Hybrid orthoses for deficient locomotion, "in Advances in External Control of Human Extremities VIII. Yugoslav Committee for ETAN, Beograd, 1984, pp. 23-32.

[41] R. Tomovic and R. McGhee, "A finite state approach to the synthesis of bioengineering control systems," IEEE Trans. Human Fact. Eler'tron., vol. HFE-7, no. 2, pp. 122-128, 1966.

[42] R. Tomovic et al., "Hybrid actuators for orthotic systems: Hybrid assistive systems," in IV Advances in External Control of Human Extremities (ECHE). Yugoslav Committee for ETAN, Beograd, 1972, pp. 231-238.

[43] R. Tomovic, D. Popovic, and F. Gracanin, "A technology for selffitting of orthoses," in VI Advances in External Control of Human Extremities (ECHE). Yugoslav Committee for ETAN, Beograd. 1978, pp. $1-15$.

[44] R. Tomovic et al., "Logical control of A/K prosthesis," Final Rep., VA Center, New York, NY, 1980.

[45] R. Tomovic et al., "Bioengineering actuator with nonnumerical control," in Proc. IFAC Conf. Orthotics Prosthetics, Columbus, $\mathrm{OH}$, 1982,pp. $145-151$

[46] R. Tomovic, "Control of assistive systems by external reflex arcs," in Advances in External Control of Human Extremities IX. Yugoslav Committee for ETAN, Belgrade, 1984, pp. 7-21.

[47] R. Tomovic and G. Bekey, "Robot control by reflex actions," in Proc. 1986 Conf. IEEE Robot. Automat., San Francisco, CA, vol. 1 1986, pp. $240-248$

[48] R. Tomovic, D. Popovic, and D. Tepavac, "Adaptive reflex control of assistive systems," in Advances in External Control of Human Extremities IX. Yugoslav Committee for ETAN, Beograd, 1987, pp. 207-214.

[49] L. Vodovnik et al., "Modification of abnormal motor control with functional electrical stimulation of peripheral nerves, in Recent Achievements in Restorative Neurology, Eckles and Dimitrijevic, Eds., 1985, pp. 43-54.

[50] G. Wilhere et al., "Design and evaluation of a digital closed-loop controller for the regulation of muscle force by recruitment modulation,"'IEEE Trans. Biomed. Eng., vol. BME-32, pp. 669-676, Sept. 1985.

[51] N. A. Bernstein, "Trends and problems in the study of investigation of physiology of activity," in The Coordination and Regulation of Movements, N. A. Bernstein, Ed. Oxford: Pergamon. (Originally published in Questions of Philosophy, Vopr. Filos., vol. 6, pp. 7792, 1961.)

[52] R. B. Stein, "What muscle variable(s) does the nervous system control in limb movements," Behavioral Brain Sciences, vol. 5, pp. 535$578,1982$.

[53] D. Tepavac et al. "Knowledge base for reflex control," in Proc. XXIX Yugoslav Conf. ETAN, Beograd, pp. IV.232-239, 1986.

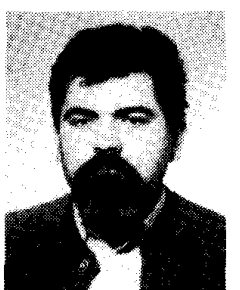

Dejan Popovic was born in Belgrade, Yugoslavia in 1950 . He was graduated in 1974 and received the M.S. and Ph.D. degrees in 1977 and 1981 in the field of control engineering and biomechanical engineering, all at the Faculty of Electrical Engineering, University of Belgrade.

$\mathrm{He}$ is Professor at the Department of Electrical Engineering, University of Belgrade. He is also an Adjunct Professor at the Department of Physiology, University of Alberta, Edmonton, Canada. His major activity is in the field of biomechanical analysis and modeling, design of assistive systems and control methods for motion assessment of handicapped.

Dr. Popovic is a member of ISB, ESB, EFMBE, Yugoslav Society for ETAN, and President of Yugoslav Society for Biomedical Engineering. 


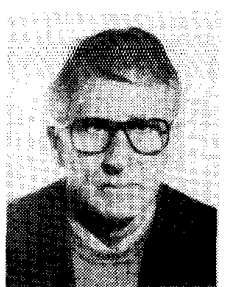

Rajko Tomović was born on November 1, 1919 in Baja, Hungary. He was graduated from the Faculty of Electrical Engineering, Belgrade, in 1946 and received the Ph.D. degree in computer development in 1952 in Belgrade.

In 1961, became Full Professor at the Faculty of Electrical Engineering, Belgrade, in the area of computer and system science. Since 1962, he has been teaching regularly and doing research at the University of California, Los Angeles, and the University of Southern California, Los Angeles. He has been invited as a Lecturer at major universities in the US, Europe, USSR, and Japan. He has published several books on computer science, nonlinear control and, recently, on intelligent robotic systems. He has also published about 90 scientific papers in international journals. Currently, he is in charge of a Yugoslav-U.S. project in artificial intelligence and intelligent robotic systems.

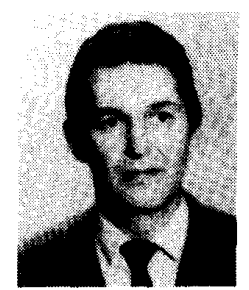

Laszlo Schwirtlich was born in 1946 in Zrenjanin, Yugoslavia. He received the B.S. degree in medicine from University of Belgrade in 1972, with a speciality in clinical medicine and rehabilitation in 1977 and the Ph.D. degree in medicine in 1986.

He has been with the Rehabilitation Institute "Dr Miroslav Zotović" Belgrade, Yugoslavia since 1975 . He is a Professor of Kinesytherapy in the School for Physical Therapy, Belgrade, Yugoslavia. His major scientific interest is in clinical EMG, motor control, and restorative neurology.

Dr. Schwirtlich is a member of Yugoslava Society for EEG and clinical neurology and Society for physical medicine and rehabilitation. 